\title{
Summary of the Technical Report on Estimating the Impact of Key Programmatic Risk Allocation Decisions on Phase 1 Bids and U.S. Department of Energy Costs
}

by J.M. Keisler and W.A. Buehring

Decision and Information Sciences Division,

Argonne National Laboratory, 9700 South Cass Avenue, Argonne, Illinois 60439

May 1996

DISTPIBUTION OF THIS DCCUMENT IS UNIMITED $K 8$

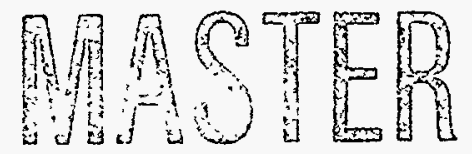

Work sponsored by United States Department of Energy, Office of Environmfental Management 


\section{DISCLAMMER}

Portions of this document may be illegible in electronic image products. Images are produced from the best available original document. 


\section{PREFACE}

This study was conducted by Argonne National Laboratory (ANL) under the direction of Mark A. Robershotte and Peter D. McLaughlin of Pacific Northwest National Laboratory (PNNL) for the Programmatic Risk Task of the Privatization Support Project. The study was carried out to provide helpful information as part of the effort to revise the Draft TWRS Privatization Request for Proposals (issued November 16, 1995). Because the work described in this report did not begin until December 1995 and the results were needed by mid-January 1996, time constraints did not allow the analysis to be conducted at the level of detail that this important topic deserves. Nevertheless, with the cooperation of some of the privatization team staff and Scully Capital (the project's financial advisers), ANL and PNNL prepared the results and provided them to the Source Evaluation Board, Tank Waste Remediation System Privatization, for consideration as the final request for proposals was being prepared.

The authors thank Pete McLaughlin, Mark Robershotte, and Mark Weimar (PNNL) for their advice, cooperation, and good spirit, as well as Chris Klaus (ANL) for his assistance. We also thank Mark Weimar, Bill Richmond, and Megan Lerchen, the subject-matter experts from PNNL who allowed us to conduct interviews and improve our understanding of complex programmatic risk topics. Finally, we thank Carol Sohn (U.S. Department of Energy) for her interest and support and other members of the privatization team for their assistance. 


\section{CONTENTS}

PREFACE …...................................................................................................

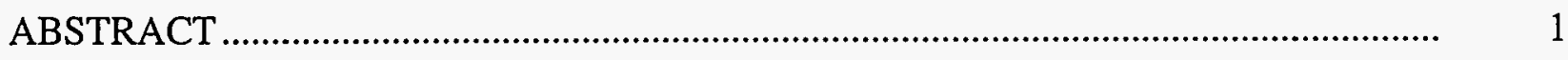

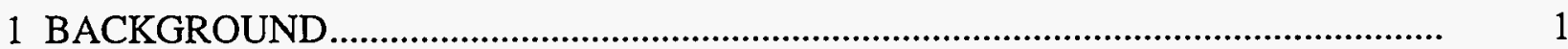

2 APPROACH ...................................................................................................

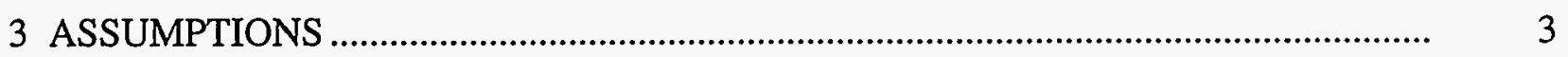

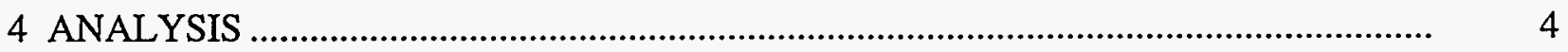

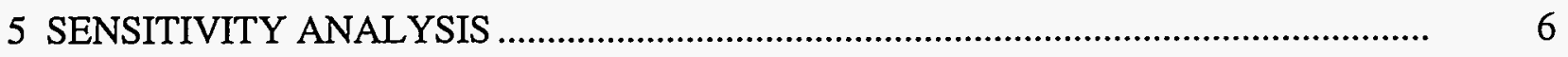

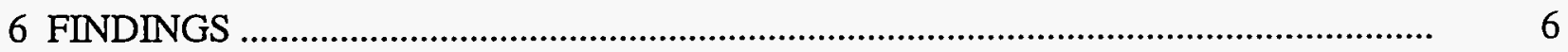

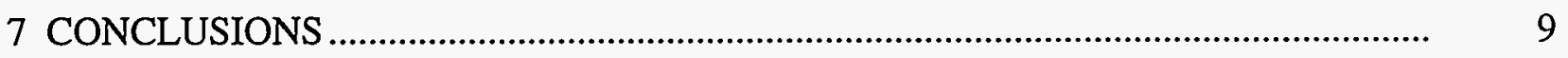

\section{FIGURES}

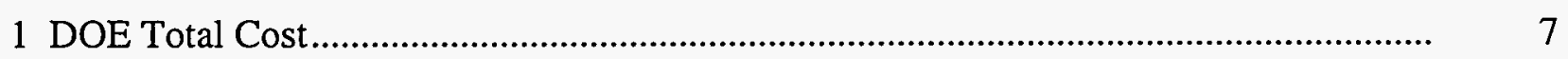

2 Sensitivity of DOE Cost to Changes from the Request for Proposals .............................. 8

\section{TABLE}

1 Risk Allocations and Results for the Four Strategies. 


\title{
SUMMARY OF THE TECHNICAL REPORT ON ESTIMATING THE IMPACT OF KEY PROGRAMMATIC RISK ALLOCATION DECISIONS ON PHASE 1 BIDS AND U.S. DEPARTMENT OF ENERGY COSTS
}

by

J.M. Keisler and W.A. Buehring

\begin{abstract}
The U.S. Department of Energy (DOE) is privatizing the processing of hazardous and radioactive tank waste at the Hanford Site in Washington State. As part of the privatization process, a request for proposals describing the conditions and DOE's expectations for contractor performance and responsibilities was issued. Argonne National Laboratory and Pacific Northwest National Laboratory collaborated to analyze programmatic risks and costs associated with privatization. They examined nine major risks to determine financial impacts on the prospective vendors and DOE for three alternative risk allocations: (1) DOE bears the risk, (2) the vendor bears the risk, or (3) the risk is shared. With the help of a subject-matter expert, each risk was characterized by estimating potential consequences and likelihood of occurrence. A financial risk model was developed to estimate the total cost to DOE for a given risk allocation strategy covering all nine risks. Results showed that it is financially advantageous to DOE to bear some risks, share some others, and assign some to the vendor.
\end{abstract}

\section{BACKGROUND}

As part of the U.S. Department of Energy (DOE) effort to privatize the processing of hazardous and radioactive waste at the Hanford Site in Washington State, Argonne National Laboratory collaborated with the Pacific Northwest National Laboratory (PNNL) Privatization Support Team to analyze the impacts of several programmatic risks on potential costs to DOE. The purpose of this effort, which began in early December 1995, was twofold:

- Estimate the effect of selected major risks, such as interest rates and inflation, on Phase 1 bids and on the cost to DOE for different risk allocations between a vendor and DOE.

- Develop an analytic framework for evaluating and comparing the effects of risks on costs to DOE and the effects of incentives inherent in allocating those risks. 
This report summarizes the findings of this effort for the Source Evaluation Board and DOE management. A more detailed technical report contains descriptions of risks, assumptions, methodologies, and results.

\section{APPROACH}

Prompting this analysis was the concern that different allocations of key risks are likely to considerably affect the final cost to DOE. Vendor responses to the draft request for proposals (RFP) verified the importance of risk allocation in obtaining reasonable financing.

The full range of risks that could be candidates for allocation was examined. Nine major risks were selected for closer examination on the basis of an initial expectation that they could be significantly affected by the risk allocation strategy. These major risks were:

- Interest rate. Interest rates can change between the time the bid is made and financing is approved.

- Inflation. The vendor is exposed to inflation risk in the draft RFP.

- Changes in law. Applicable laws and regulations can change.

- Permitting. The vendor may not be able to obtain the necessary permits.

- Waste stream $C$. This waste is probably the most technically difficult to process.

- Appropriation. Congress may not appropriate adequate funding for planned activities.

- Decontamination and decommissioning (D\&D). D\&D may be more costly than expected.

- Other uncontrollable circumstances. Examples of possible uncontrollable circumstances include law suits, sabotage, earthquakes, and tornadoes.

- Not to exceed (NTE) price risk. The contract pricing arrangement could be NTE, as in the draft RFP, or it could be a form of a target price that allows selected adjustments. 
Each risk was characterized through discussions with PNNL privatization staff experts, and estimates of potential consequences and the likelihood of their occurrence were developed for each of three possible risk allocations (defined in detail in the technical report):

- DOE bears all the risk.

- Risk is shared.

- Vendor bears all the risk.

A calculation procedure (a financial risk model) that estimates the range and likelihood of different values for vendor cost, the expected vendor bid, and the ultimate cost to DOE (the sum of payments to vendor and the direct DOE cost) was developed. The vendor response to cost uncertainty and magnitude was measured by estimating changes in the internal rate of return, the debt fraction, and the debt interest rate.

\section{ASSUMPTIONS}

The results derived in this study required numerous subjective and simplified assumptions about the risks, the vendor's perception of risks, and the effect on costs to DOE. Several limitations were acknowledged:

- There may be individuals who are better informed than those who participated in the study.

- Vendors are not all the same.

- Vendors can view risks holistically or otherwise.

- Results cannot be safely extrapolated beyond the range of risks considered.

If this model is used for policy decisions, decision makers should not interpret the results literally. If more definitive analysis or understanding is required, more information should be obtained. 


\section{ANALYSIS}

Estimates of risk consequences and probabilities were used with the financial risk model to prepare rough estimates of the impacts of various risk allocation strategies. Table 1 shows the results for four relevant strategies:

- Strategy 1. All listed risks are allocated to DOE.

- Strategy 2. Risks are allocated as in the revised RFP under consideration as of January 20, 1996.

- Strategy 3. Risks are allocated as in the revised RFP, plus NTE risk is allocated to the vendor.

- Strategy 4. All listed risks are allocated to the vendor.

These results demonstrate that Strategy $1-\mathrm{DOE}$ takes all the risks (all results are for one vendor) - has the lowest required internal rate of return (IRR), the highest allowed debt fraction, the lowest debt interest rate, and, therefore, the lowest DOE payment to the vendor. However, the total DOE cost under this strategy is considerably higher than that under some other strategies because of the expected performance of the vendor when DOE bears certain risks.

Strategy 4 results in an even higher cost for DOE. In this strategy, the vendor takes all the risks. This strategy results in the highest $\mathbb{R R}$, the lowest debt fraction, the highest debt interest rate, and the highest DOE payment to the vendor. These results indicate that this strategy probably cannot be financed and therefore is unrealistic. The risk premium the vendor would need would drive the costs up so much that the project would be infeasible.

Strategy 2 - the RFP case - shows the lowest expected cost to DOE of the four strategies, that is, $\$ 744$ million. In this case, the vendor bears the interest rate, waste stream C, and the appropriation risks. Risks of permitting, D\&D, law suits, and NTE are shared. DOE bears inflation, change in law, sabotage, earthquake, and tornado risks. The DOE payment to the vendor is $\$ 34$ million more than it is under Strategy 1. The major difference is the reduction in DOE cost increment by more than $\$ 229$ million. The total DOE payments therefore decline by approximately $\$ 195$ million from those under Strategy 1 .

A variation of the RFP case was also examined (Strategy 3). The only difference was that the vendor took the NTE risk instead of the target price risk being shared, as is assumed under the RFP Strategy (2). The results show a cost increase of $\$ 42$ million to DOE. Some members of the privatization team believed this increase is underestimated. The characterization of the NTE risk to the vendor may not capture the full degree of uncertainty associated with the NTE risk; at present, this option is assumed to be the same as using a firm fixed price. Further investigation in characterizing the NTE risk is recommended. 
TABLE 1 Risk Allocations and Results for the Four Strategies

\begin{tabular}{|c|c|c|c|c|}
\hline \multirow[b]{2}{*}{ Type of Consequence } & \multicolumn{4}{|c|}{$\begin{array}{c}\text { Consequence per Risk Allocation } \\
\text { Strategy Number and Name }\end{array}$} \\
\hline & 1: DOE & 2: RFP & $\begin{array}{l}\text { 3: RFP + NTE } \\
\text { to Vendor }\end{array}$ & 4: Vendor $^{\mathrm{a}}$ \\
\hline \multicolumn{5}{|l|}{ Bearer of risk } \\
\hline Interest rate & DOE & Vendor & Vendor & Vendor \\
\hline Inflation & DOE & DOE & DOE & Vendor \\
\hline Changes in law & DOE & DOE & DOE & Vendor \\
\hline Permitting & DOE & Shared & Shared & Vendor \\
\hline Waste stream C & DOE & Vendor & Vendor & Vendor \\
\hline Appropriation & DOE & Vendor & Vendor & Vendor \\
\hline $\mathrm{D} \& \mathrm{D} / \mathrm{RCRA} \mathrm{b}^{\mathrm{b}}$ & DOE & Shared & Shared & Vendor \\
\hline Law suit & DOE & Shared & Shared & Vendor \\
\hline Sabotage & DOE & DOE & DOE & Vendor \\
\hline Earthquake & DOE & DOE & DOE & Vendor \\
\hline Tornado & DOE & DOE & DOE & Vendor \\
\hline NTE price & DOE & Shared & Vendor & Vendor \\
\hline \multicolumn{5}{|l|}{ Result due to vendor response (\%) } \\
\hline Required internal rate of return & 11.6 & 14.3 & 15.6 & 30.3 \\
\hline Debt fraction & 86.6 & 82.7 & 78.5 & 30.6 \\
\hline Debt interest rate & 9.3 & 9.8 & 10.0 & 11.6 \\
\hline \multicolumn{5}{|l|}{ Cost to DOE $\left(10^{3} \$\right)^{c}$} \\
\hline Payment to vendor & 602,255 & 636,530 & 664,195 & $1,397,921$ \\
\hline Mean cost increment & 336,731 & 107,625 & 121,563 & 60,400 \\
\hline Risk & 133,409 & 82,517 & 91,856 & 70,675 \\
\hline Total cost & 938,986 & 744,155 & 785,758 & $1,458,321$ \\
\hline \multicolumn{5}{|c|}{ a Strategy 4 is considered financially infeasible. } \\
\hline \multicolumn{5}{|c|}{ b $\mathrm{RCRA}=$ Resource Conservation and Recovery Act. } \\
\hline $\begin{array}{l}\text { Cost results shown are exact mode } \\
\text { cost is known to, for example, six }\end{array}$ & $\begin{array}{l}\text { after } 1, \\
\text { significe }\end{array}$ & imulati & d do not imply & DOE total \\
\hline
\end{tabular}


The costs shown in Table 1 summarize the results of 1,000 simulations conducted to account for the uncertain cost distributions. The uncertainty in the cost distributions facing DOE can be appreciated by examining graphs of probability versus cost. A comparison of the graphs in Figure 1 illustrates that DOE's total cost is higher when the risk allocation is at either extreme (i.e., all risks to DOE in Figure 1a or all risks to vendor in Figure 1c) than it is when risks are allocated as in the RFP (Figure 1b).

\section{SENSITIVITY ANALYSIS}

A sensitivity analysis of the total cost to DOE was performed by changing the allocation of individual risks from their status in the current RFP while keeping the rest of the risk allocations the same. The most critical risks to allocate correctly appear to be NTE, inflation, D\&D/RCRA, and permitting, as seen in Figure 2. Changing the allocation of the other risks results in relatively minor potential cost increases or cost savings. If vendors appear to be more concerned about risks with low cost impact predicted by the model (e.g., if vendors demand an additional $\$ 50$ million to accept the waste stream $\mathrm{C}$ risk), DOE should consider offering concessions for taking those risks (i.e., accept the risk rather than pay the premium) because they have symbolic value or because the vendors are more pessimistic than DOE is about the situation. If vendors are more willing to accept a risk than predicted, DOE may or may not benefit from trying to obtain concessions, depending on how total costs, not just payments to the vendor, are expected to change.

\section{FINDINGS}

Preliminary findings, based on this analysis, include the following:

- Forcing the vendor to bear risks that the vendor cannot control increases costs to DOE in the long term because the vendor incorporates a large risk premium.

- If the vendor can influence the outcome, sharing the risk or forcing the vendor to bear the risk reduces costs to DOE (e.g., sharing the risk associated with permitting).

- The difference between the most and least effective risk allocation strategies for the nine risks is an increase in cost to DOE of more than $\$ 200$ million per vendor. Larger cost differences were found for risk allocation strategies that probably cannot be financed.

- In all cases, DOE can expect higher costs than if there are no risks. 

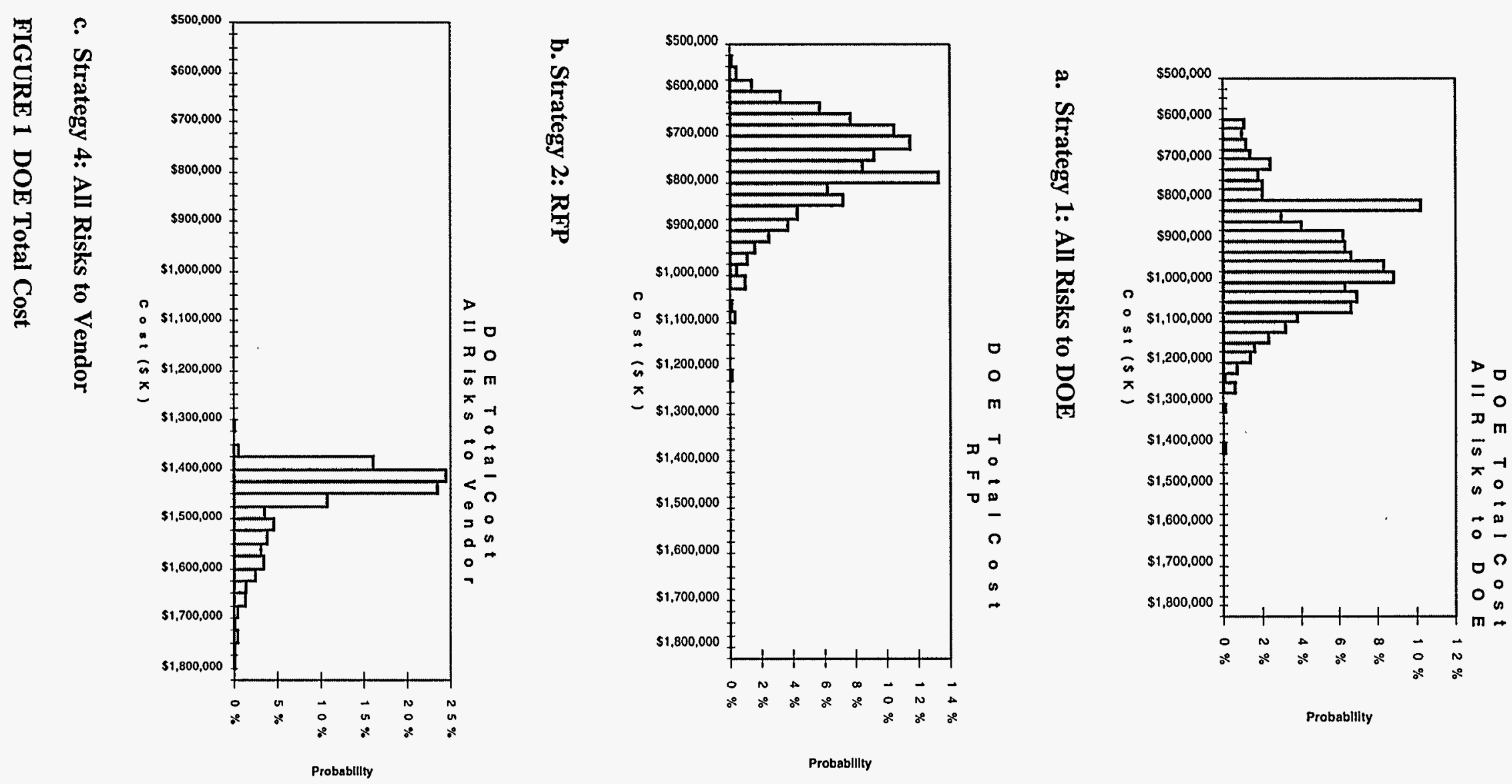


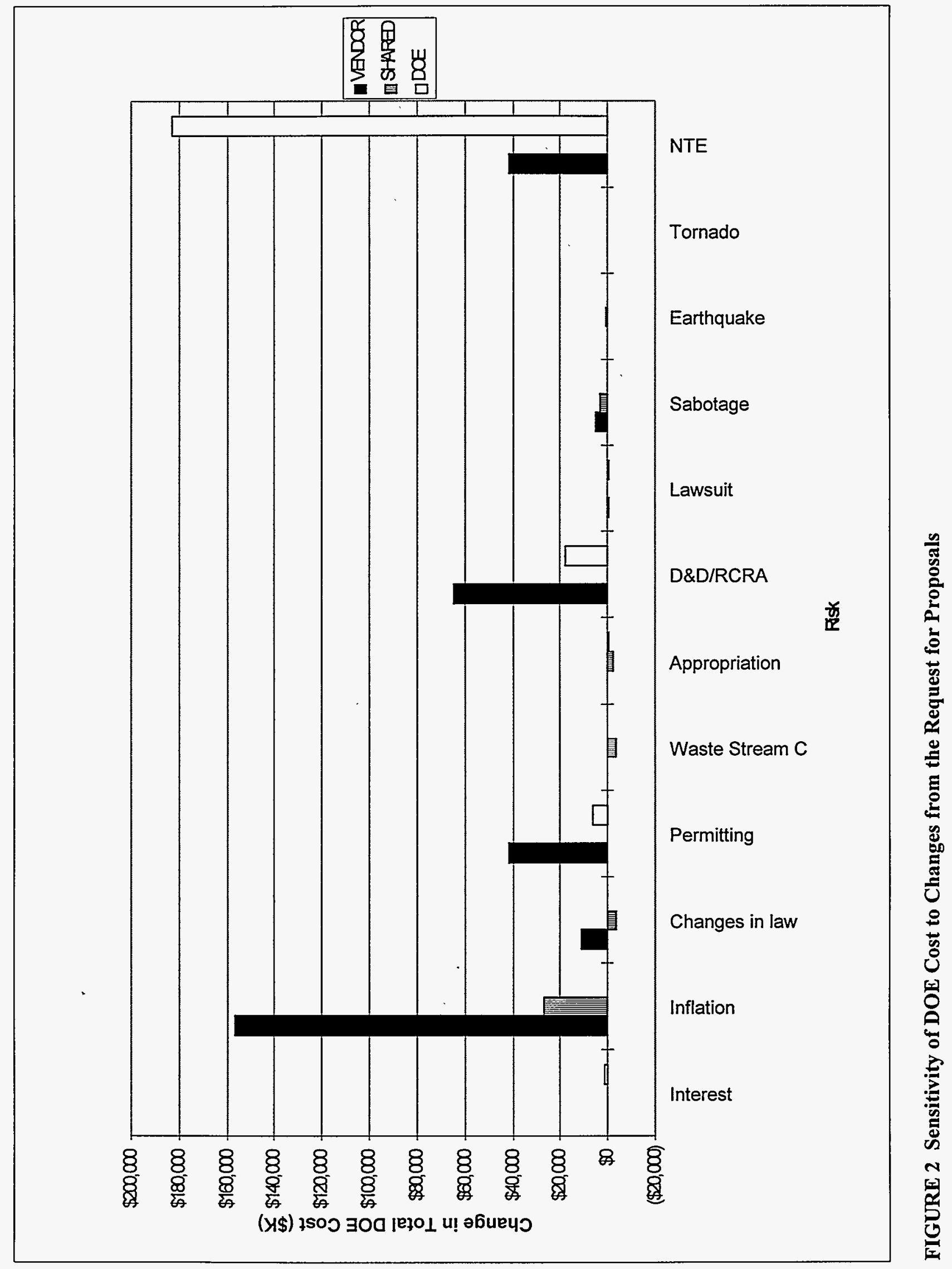


- The top risks for further investigation are $\mathrm{D} \& \mathrm{D}$, permitting, inflation, and NTE price risk.

- A combination of DOE bearing some risks and sharing others with the vendor appears to offer an attractive financial situation compared to the draft RFP conditions.

\section{CONCLUSIONS}

This analysis shows that a very attractive strategy for DOE is to bear some risks, share some others, and assign the remaining ones to the vendor. One purpose of this task was to provide DOE with some evidence about the potential consequences of requiring vendors to bear the risk. The model results indicate it would be very expensive for vendors to bear all the risks. The cost to DOE consists of two components: the direct cost to DOE and the payment to the vendor. To the extent that DOE wants vendors to bear large risks (and therefore large cost uncertainties), the vendors are likely to ask for very high contingencies. The cost to DOE to reduce the uncertainty in its cost by making the vendors bear risks is a very high expected payment to the vendor. Furthermore, the sensitivity analysis suggests that differences in how DOE and the vendor perceive risks could be considered during contract negotiations to determine when concessions can affect total DOE costs either neutrally or favorably.

As a possible next step, the financial risk model could be enhanced and documented to allow its ongoing use in support of new RFP issues (e.g., other risks) and negotiations (e.g., analysis of costs for DOE to share or bear selected risks). Additional effort to characterize the risk consequences and their likelihood of occurrence is recommended for both the specified risks and the new risks that become apparent and are important to DOE or the vendor. 